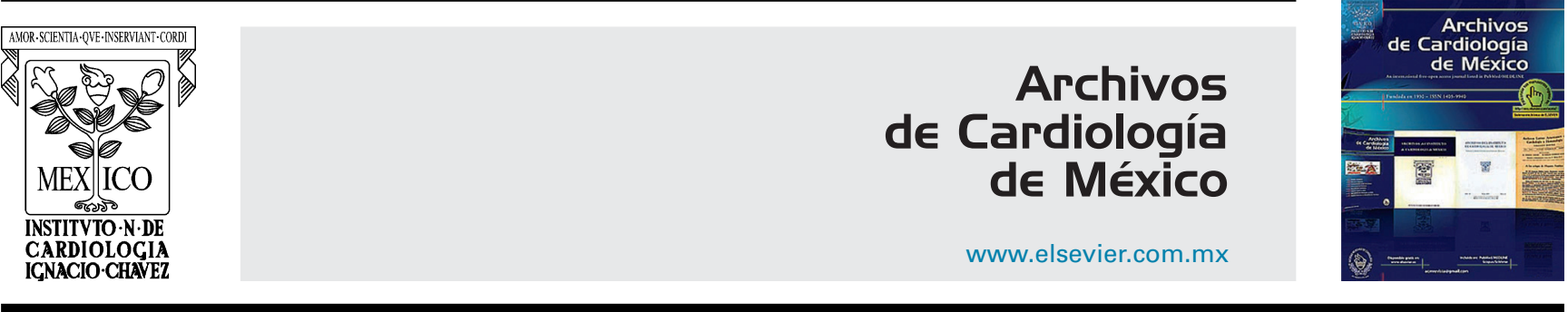

CLINICAL RESEARCH

\title{
Comparison of auscultatory and oscillometric BP measurements in children with obesity and their effect on the diagnosis of arterial hypertension
}

\author{
Salvador Fonseca-Reyes ${ }^{a, *}$, Enrique Romero-Velarde ${ }^{\mathrm{b}}$, Edith Torres-Gudiño ${ }^{\mathrm{a}}$, \\ Daniel Illescas-Zarate ${ }^{\mathrm{b}}$, Avril M. Forsyth-MacQuarrie ${ }^{a}$

\begin{abstract}
a Instituto de Investigación Cardiovascular, Centro Universitario de Ciencias de la Salud, Universidad de Guadalajara, Nuevo Hospital Civil de Guadalajara, Mexico

b Instituto de Nutrición Humana, Centro Universitario de Ciencias de la Salud, Universidad de Guadalajara, Nuevo Hospital Civil de Guadalajara, Mexico
\end{abstract}

Received 15 June 2016; accepted 16 January 2017

\section{KEYWORDS \\ Blood pressure \\ measurement; \\ Oscillometric \\ devices; \\ Childhood \\ hypertension \\ diagnosis; \\ Mexico}

\begin{abstract}
Objective: The level of agreement between two blood pressure (BP) reading methods, auscultatory vs oscillometric, was examined using a mercury sphygmomanometer and an electronic device in children and adolescents with different levels of obesity. The readings were compared to determine their impact on the diagnosis of pre-hypertension/hypertension.

Methods: Blood pressure readings were taken in children with obesity (body mass index $\geq$ 95th percentile) and severe obesity ( $\geq 120 \% 95$ th percentile). Bland-Altman analysis and Intraclass Correlation Coefficient were used to determine the agreement between measurements. Results: The mercury sphygmomanometer readings were lower than those obtained with the electronic device for both systolic and diastolic BP $(P=.01$ and $P=.001$, respectively).

The mean systolic and diastolic BP differences between the oscillometric vs first mercury reading were $4.2 / 10.2 \mathrm{~mm} \mathrm{Hg}$, respectively. A large difference was observed between the BP measurement methods. The ICC showed regular to moderate reliability for the systolic BP (.595), but poor for the diastolic BP (.330). Screening using the first of three mercury measurements showed that $10.4 \%$ of the children and adolescents had BPs within the prehypertension/hypertension range. This was reduced to $5.2 \%$ when the mean of three mercury readings was used.

Conclusions: Large discrepancies were observed in both the systolic and diastolic BP. These differences are not clinically acceptable as to consider the two instruments interchangeable. The
\end{abstract}

\footnotetext{
* Corresponding author at: Hospital Civil de Guadalajara "Dr. Juan I. Menchaca", Salvador Quevedo y Zubieta 750, Edificio Anexo 3er Piso, C.P. 44340 Colonia Independencia. Guadalajara, Jalisco, Mexico.

E-mail address: salvadorf@mail.hcg.udg.mx (S. Fonseca-Reyes).
} 


\author{
PALABRAS CLAVE \\ Medición de presión \\ arterial; \\ Dispositivos \\ oscilométricos; \\ Diagnóstico \\ de hipertensión \\ en niños; \\ México
}

electronic device readings were higher, and they overestimated the diagnosis of hypertension. ( 2017 Instituto Nacional de Cardiología Ignacio Chávez. Published by Masson Doyma México S.A. This is an open access article under the CC BY-NC-ND license (http://creativecommons. org/licenses/by-nc-nd/4.0/).

\section{Comparación de la medición de PA auscultatoria y oscilométrica en niños con obesidad y su efecto en el diagnóstico de hipertensión arterial}

\begin{abstract}
Resumen
Objetivo: Para conocer el grado de concordancia entre 2 métodos de medición de presión arterial (PA), auscultatorio vs oscilométrico se utilizó un esfigmomanómetro de mercurio y un dispositivo electrónico en niños y adolescentes con diferentes grados de obesidad. Las lecturas fueron comparadas para conocer su impacto en el diagnóstico de prehipertensión/hipertensión. Método: Se midió la PA a niños con obesidad (percentil 95 del índice masa corporal) y obesidad severa (120\% del percentil 95). Utilizamos análisis de Bland-Altman y Coeficiente de Correlación Intraclase $(\mathrm{CCl})$ para conocer acuerdo entre mediciones.

Resultados: Las lecturas con esfigmomanómetro de mercurio fueron más bajas que con el electrónico para la PA sistólica y diastólica $(p=0.01$ y 0.001 , respectivamente).

El promedio de las diferencias en sistólica y diastólica entre oscilométrico vs. primera medición con mercurio fue de $4.2 / 10.2 \mathrm{~mm} \mathrm{Hg}$ respectivamente. Se observó una gran diferencia de las mediciones entre los métodos de medición de PA. El CCI mostró una confiabilidad regular a moderada para la sistólica (0.595) pero pobre para la diastólica (0.330). El tamizaje con una medición mediante mercurio mostró que el $10.4 \%$ de los niños y adolescentes tenían PA en el rango de prehipertensión/hipertensión, pero se redujo a un $5.2 \%$ con el promedio de 3 mediciones.

Conclusiones: Se observaron grandes discrepancias en la PA sistólica y diastólica. Tales diferencias no son clínicamente aceptables como para considerar equivalentes los 2 instrumentos. Las mediciones realizadas en este estudio con dispositivo electrónico fueron más altas y sobre estimaron el diagnóstico de hipertensión.

( 2017 Instituto Nacional de Cardiología Ignacio Chávez. Publicado por Masson Doyma México S.A. Este es un artículo Open Access bajo la licencia CC BY-NC-ND (http://creativecommons. org/licenses/by-nc-nd/4.0/).
\end{abstract}

\section{Introduction}

Both arterial hypertension $(\mathrm{AH})$ and obesity are major public health problems in Mexico. ${ }^{1}$ Obesity is steadily increasing in the general population, and in children and adolescents, with a prevalence close to $17 \%{ }^{2}$ The 2012 National Health and Nutrition Survey in Mexico showed a similar prevalence of obesity, in both children between 5 and 11 years (14.6\%) and adolescents $12-19$ years old (13.3\%). ${ }^{1}$ In developed and developing nations the prevalence of severe childhood obesity is also increasing, with reported values ranging from $1 \%$ to almost $8 \% .^{3-7}$ There is also evidence that both obesity and high blood pressure (BP) levels in children can persist into adulthood. The probability of developing $\mathrm{AH}$ can increase three-fold with severe childhood obesity, reaching a prevalence up to $20 \%$, making this group highly susceptible to future cardiovascular damage. ${ }^{7-11}$

With this in mind, different international organisms recommend early $\mathrm{AH}$ detection with BP screening starting at three years of age. ${ }^{12,13}$ However, this relatively simple and economical procedure is not done often enough by many general practitioners and pediatricians. ${ }^{14,15}$ Also, taking correct $B P$ levels requires the right measurement technique, along with two other critical components; the type of sphygmomanometer and a cuff corresponding to the arm circumference. ${ }^{12,16}$

Mercury sphygmomanometers are disappearing from the clinical setting, and replaced by oscillometric monitors for routine BP measurements. The growing prevalence of childhood overweight and obesity has caused larger arm circumferences, and thus the need for proper sized cuffs to obtain a correct BP reading. ${ }^{17}$ Unfortunately, the cuff-size selection is very limited when dealing with electronic BP devices.

Our main objective was to compare auscultatory technique $\mathrm{BP}$ readings using a mercury sphygmomanometer vs oscillometric device $B P$ readings, and evaluate the effect of these measurements on the diagnosis of prehypertension/hypertension in study subjects visiting an obesity clinic. We also wanted to determine the requirements for different cuff sizes used in BP readings.

\section{Methodology}

This cross-sectional study included children and adolescents of both genders with obesity, defined as body mass index $(\mathrm{BMI}) \geq 95 \%$ percentile, or with severe obesity, defined as $\mathrm{BMI}$ $\geq 120 \%$ of the age and sex specific 95 th percentile, and seen 
at the outpatient pediatric obesity clinic of the New Civil Hospital of Guadalajara, Mexico. The parents gave written informed consent for their children to participate. The study was approved by the hospital bioethics committee. Before taking BP readings, both subjects and their parents were asked if their BP had been taken on a previous occasion, and if they had been ever diagnosed with $\mathrm{AH}$. Information such as age, weight, height, BMl and mid-arm circumferences of both upper limbs was also captured. Blood pressure readings were done following international recommendations. ${ }^{12,13,16}$

\section{Blood pressure measurement}

After at least five minutes rest while sitting down, the procedure was explained to each child. They were asked not to speak during the readings. The measurements were done by an observer trained in the technique, from 9 to $11 \mathrm{am}$ and at a room temperature of $24-26^{\circ} \mathrm{C}$. The BP was first taken automatically, using two calibrated electronic sphygmomanometers (Omron HEM $725 \mathrm{CIC}$, OMRON Healthcare, Kyoto, Japan) handled simultaneously by said observer. Next, a mercury sphygmomanometer (Tycos ${ }^{\circledR}$ Ins., North Carolina, USA) was used for the auscultatory technique $B P$ readings, handled by a different observer. With both types of apparatus, the subject was seated, their arms were uncovered to the shoulder, the back was supported and the legs were uncrossed and supported by a flat surface. A cuff appropriate for the arm circumference was used, centered over the brachial artery, covering 40 and $80 \%$ of the arm width and length, respectively. ${ }^{12}$ Both devices were placed on the desk at the level of the 4th intercostal space. The BP was measured only once in both arms with the electronic devices. Another three consecutive readings were taken, this time using the mercury sphygmomanometer, with a one minute interval between each measurement, using the arm with the highest BP detected with the automatic devices. Air was let out at a speed of $2 \mathrm{~mm} \mathrm{Hg}$ per heartbeat. The first of two identified continuous beats was registered as the systolic pressure (Korotkoff Phase I), and the disappearance of the last beat as the diastolic pressure (Kortokoff Phase V).

\section{Diagnosis of the BP level}

Diagnosis of the BP level was done using the criteria of the Hypertension Working Force for Children and Adolescents of the National High Blood Pressure Education Program and the American Academy of Pediatrics. ${ }^{12}$ Blood pressure was considered normal when the systolic and diastolic BP were below the 90th percentile for age, gender and stature, and $\mathrm{AH}$ was defined if the systolic and/or diastolic BP was above the 95th percentile. Systolic and/or diastolic BP that were $\geq$ 90th percentile but $<95$ th percentile, or $\geq 120 / 80 \mathrm{~mm} \mathrm{Hg}$, even if below the 90th percentile, were considered to be pre-hypertension (pre-AH).

\section{Statistical method}

Both descriptive and analytic statistics were used. The continuous variables are shown as average, standard deviation and confidence intervals, and the categoricals as absolute values and percentages. The differences in systolic and diastolic BP when using the electronic device and the mercury sphygmomanometer were evaluated separately. These differences were calculated as oscillometric minus mercury device. Also, the BP reading agreement between the two devices was evaluated with an intraclass correlation coefficient (ICC) and the Bland-Altman method. A scatter plot was created containing the differences (electronic-mercury) between the two devices, and the corresponding averages [(electronic + mercury/2)] were compared. The range of agreement was defined as the mean bias \pm 2 standard deviations. $\mathrm{A} \mathrm{Chi}^{2}$ test was used to determine if the proportion of pre-hypertension/hypertension diagnosis was equal with both devices. The significance level was $p$ equal or less than 0.05 .

\section{Results}

A total of 77 children and adolescents with obesity were included in the study. The average age was $10.8 \pm$ 2.9 years (5-17 years), $70 \%$ were masculine, and the mean waist circumference was $93.1 \pm 14 \mathrm{~cm}$ (Table 1). All of the study subjects and/or their parents denied a previous diagnosis of $\mathrm{AH}$. The systolic and diastolic BP levels were higher when measured with the electronic device, $107.8 \pm 14.5 / 71.4 \pm 15.8 \mathrm{~mm} \mathrm{Hg}$, when compared to the first reading obtained with the mercury sphygmomanometer, $104.0 \pm 9.6 / 61.1 \pm 9.5 \mathrm{~mm} \mathrm{Hg}(p=0.006$ and 0.001 , respectively Table 2). The second mercury sphygmomanometer systolic BP reading was lower than the first $(p=0.01)$, but no significant difference was observed between the second and third systolic BP measurements, nor between all three diastolic $B P$ readings.

\begin{tabular}{ll}
$\begin{array}{l}\text { Table } 1 \text { Demographic characteristics of the } 77 \text { study } \\
\text { subjects. }\end{array}$ \\
\hline Age (years) & $10.8 \pm 2.9$ \\
Male/Female (\%) & $70 / 30$ \\
Body Mass Index 95th percentile (\%) & 100 \\
Body Mass Index 120\% 95th percentile (\%) & 65 \\
Mid-arm circumference (cm) & $31.1 \pm 4.3$ \\
Measured arm (\%) & \\
$\quad$ Left & 59.7 \\
Right & 40.3 \\
Systolic blood pressure $(\mathrm{mm} \mathrm{Hg})$ & $104.0 \pm 9.6$ \\
Diastolic blood pressure $(\mathrm{mm} \mathrm{Hg})$ & $61.1 \pm 9.5$ \\
\hline
\end{tabular}

Table 2 Blood pressure with electronic device and mercury sphygmomanometer.

\begin{tabular}{lll}
\hline Device BP & Systolic BP & Diastolic BP \\
\hline Oscillometric & $107.8 \pm 14.5^{1}$ & $71.4 \pm 15.8^{4}$ \\
Mercury 1 & $104.0 \pm 9.6^{2}$ & $61.1 \pm 9.5^{5}$ \\
Mercury 2 & $102.0 \pm 9.8^{3}$ & $61.4 \pm 9.6$ \\
Mercury 3 & $102.0 \pm 10.2$ & $61.0 \pm 9.4$ \\
Average of 3 & $102.5 \pm 9.5$ & $61.4 \pm 9.2$ \\
\hline (1 vs 2, 2 vs 3) $\mathrm{p}<0.01^{(4 \text { vs 5) }<0.001 .}$ &
\end{tabular}


A

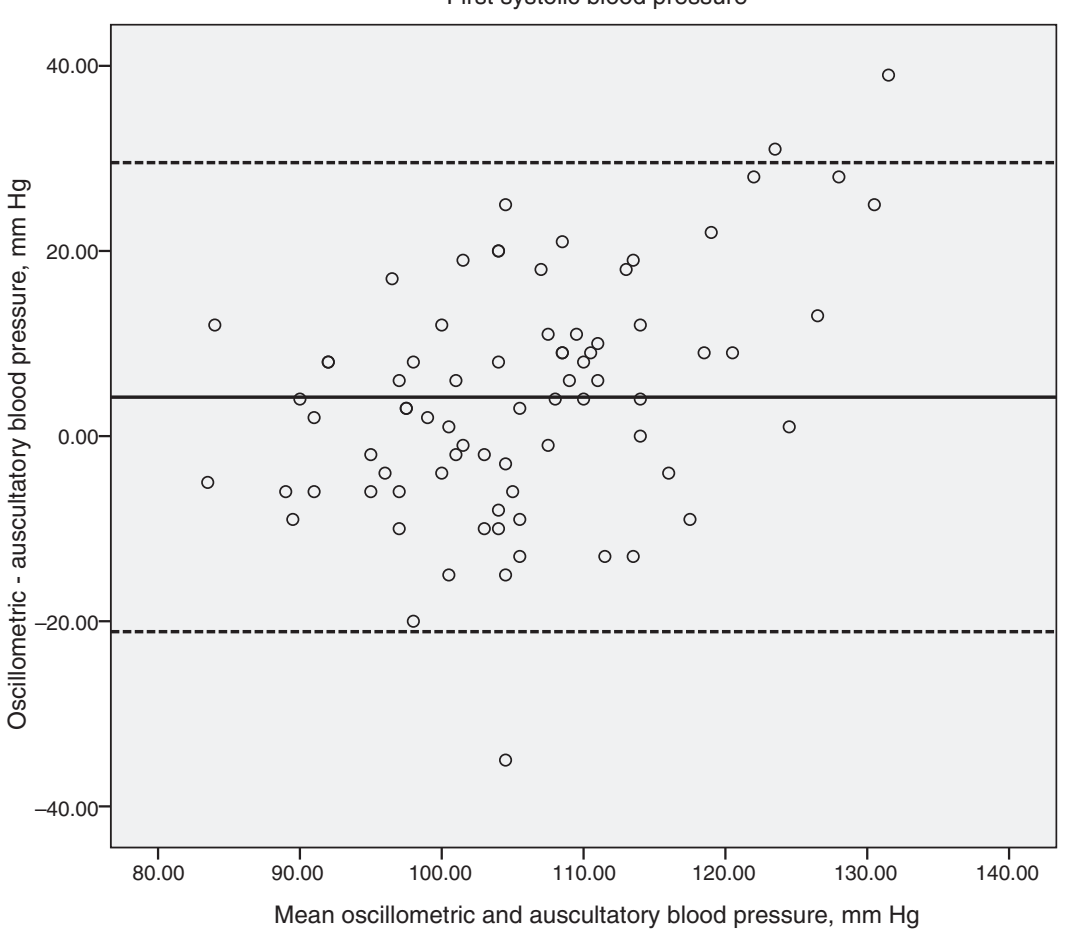

B First diastolic blood pressure

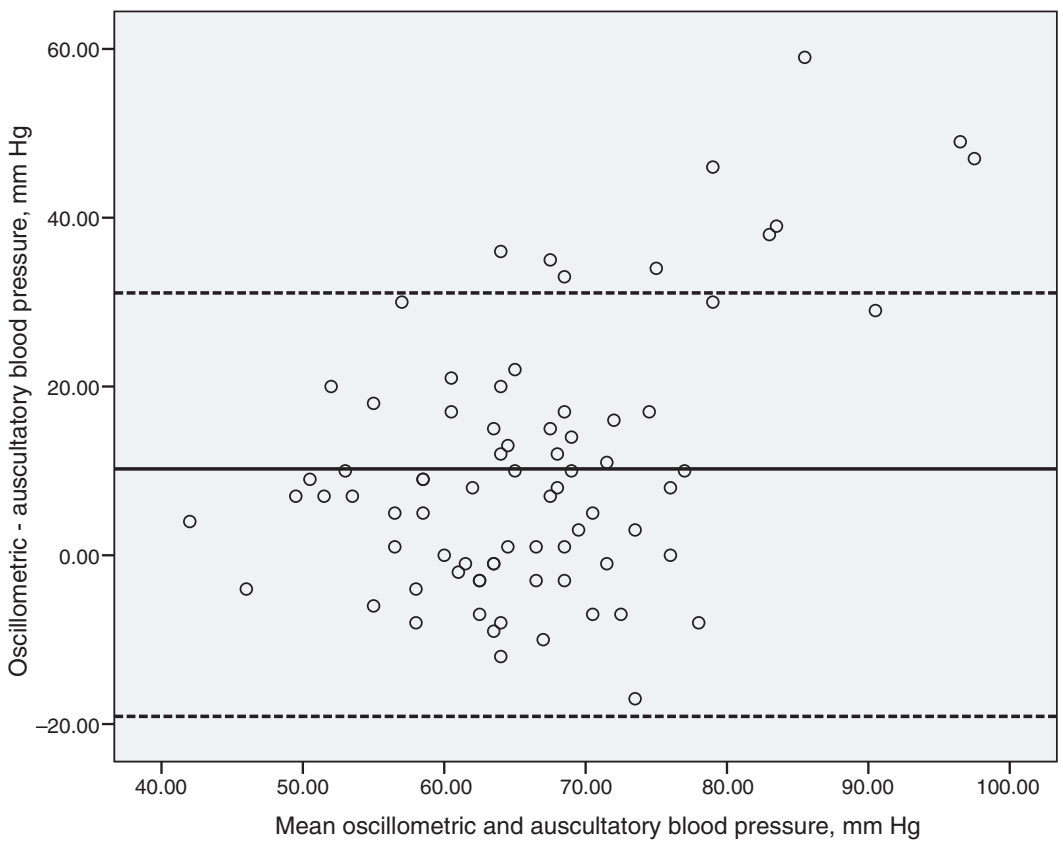

Figure 1 Magnitude of difference in first systolic (panel A) and diastolic (panel B) blood pressure readings by the oscillometric and auscultatory methods plotted against the means of systolic blood pressure readings with the 2 methods. Two broken horizontal lines represent the $95 \%$ confidence intervals for the mean difference. The solid horizontal lines represent the mean difference.

The average of the differences between the electronic device vs the first mercury reading for the systolic/diastolic $\mathrm{BP}$ was $4.2 / 10.2 \mathrm{~mm} \mathrm{Hg}$, and vs the average of the three mercury readings it was $5.2 / 10.0 \mathrm{~mm} \mathrm{Hg}$, respectively. The Bland-Altman plots of the differences along with the ample agreement limits (first mercury reading; systolic BP 29/-21 and diastolic BP $31 /-19 \mathrm{~mm} \mathrm{Hg}$, average of the three mercury readings; systolic BP 31/-20 and diastolic BP $41 /-18 \mathrm{~mm} \mathrm{Hg}$ ) reflect the large variation in these differences with a tendency to be higher at the cutoff points of $>80 y>115 \mathrm{~mm} \mathrm{Hg}$ for the systolic and diastolic BP, respectively (Figs. 1 and 2, Panels $A$ and $B$ ). 

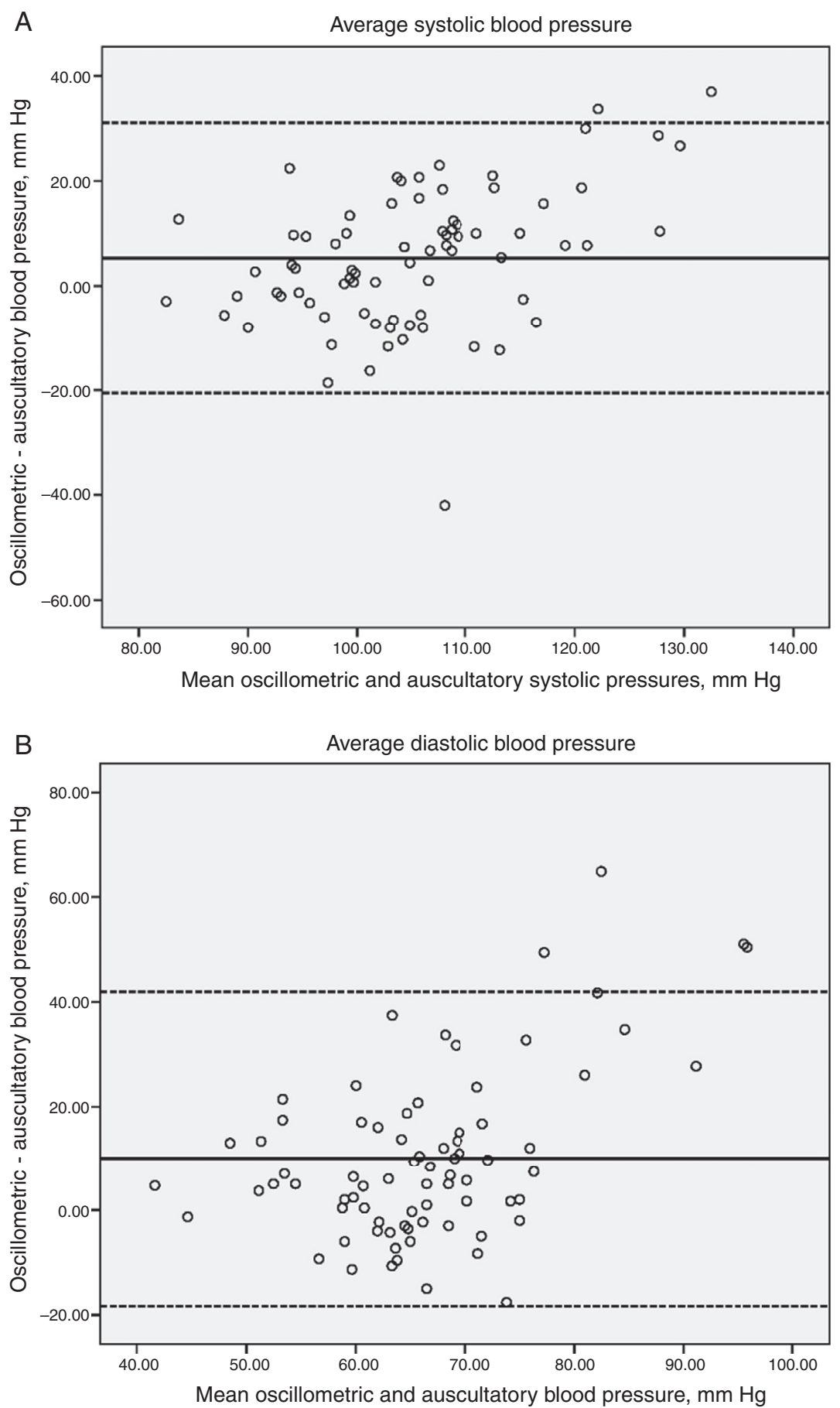

Figure 2 Magnitude of difference in average systolic (panel A) and diastolic (panel B) blood pressure readings by the oscillometric and auscultatory methods plotted against the means of diastolic blood pressure readings with the 2 methods. Two broken horizontal lines represent the $95 \%$ confidence intervals for the mean difference. The solid horizontal lines represent the mean difference.

When evaluating the agreement with the ICC, a regular to moderate reliability of $0.595(0.362$ to 0.743$)$ was observed for the systolic BP, and a poor $0.330(-0.032$ to 0.569$)$ for the diastolic BP.

Depending on the measurement method used, an important overestimation is present for the diagnosis of systolic and diastolic $\mathrm{AH}$ (BP $\geq 95$ th percentile) with the electronic device (Table 3). This is significant when the automatic measurements (37.7\%) are compared with the first mercury measurement or the average of the three mercury readings, $7.8 \%$ and $5.2 \%(p=0.001)$, respectively. The same finding was observed for the diagnosis of systolic and diastolic pre-AH ( $\geq 90<95$ th percentile), $11.6 \%$ with the automatic device vs $6.4 \%$ and $5.2 \%$ ( $p=$ NS) with mercury, the first measurement or average of the three readings, respectively. 
Table 3 Reclassification of subjects with BP in normal, prehypertension and hypertension ranges using automatic measurement vs mercury.

\begin{tabular}{lccc}
\hline & Electronic device & 1st mercury reading & Average of 3 mercury readings \\
\hline Systolic & & & $72(93.5 \%)$ \\
$\quad$ Normal & $59(76.6 \%)$ & $70(91 \%)$ & $3(3.9 \%)$ \\
Prehypertension & $5(6.5 \%)$ & $4(5.1 \%)$ & $2(2.6 \%)$ \\
Hypertension & $13(16.9)$ & $3(3.9 \%)$ & $74(96.1 \%)$ \\
Diastolic & & & $1(1.3 \%)$ \\
$\quad$ Normal & $57(74 \%)$ & $3(94.8 \%)$ & $2(2.6 \%)$ \\
Prehypertension & $4(5.1 \%)$ & $1(1.3 \%)$ & $3(3.9 \%)$ \\
Hypertension & $16(20.8)$ & & \\
\hline
\end{tabular}

Despite the fact that $100 \%$ of the subjects had been seen on multiple occasions by the general or pediatric practices, $61 \%$ denied having their BP taken before this study, $36 \%$ had one previous reading, and only $3 \%$ mentioned more than one measurement during previous consultations. Four different sized cuffs were used during the study; infant size $(7 \mathrm{~cm}$ wide) in $1.3 \%$ of the subjects, child/small-adult $(10 \mathrm{~cm})$ in $10.4 \%$, adult/standard $(12 \mathrm{~cm})$ in $66.2 \%$ and large adult $(15 \mathrm{~cm})$ in $22.1 \%$.

\section{Discussion}

Body Mass Index and BP are closely related; the everincreasing level of childhood and adolescent obesity has caused higher BP values in these populations. ${ }^{18}$ Besides detecting subjects with hypertension who may need therapeutic intervention, the objective of pediatric $B P$ readings is to identify those children or adolescents susceptible to developing $\mathrm{AH}$ later in life. ${ }^{19,20}$ In our population of severely obese children and adolescents who did not know their $\mathrm{AH}$ status, we detected that around $10 \%$ had high $\mathrm{BP}$, half of these in the hypertensive range, a higher prevalence than in non-obese children. We also found that systolic and diastolic BP readings obtained with the electronic device were significantly higher $(4.2 / 10.2 \mathrm{~mm} \mathrm{Hg})$ than those obtained with a rigorous auscultatory technique done with mercury, this based on one measurement with each apparatus. The confidence intervals obtained with the Bland-Altman method were quite ample, indicating that the values obtained with the electronic device for the systolic and diastolic BP were extremely variable. Such differences are not clinically acceptable to consider the two instruments as interchangeable.

As recommended by international guidelines, in our hypertension clinic we routinely measure BP in both arms, as up to $20 \%$ of adults have differences $>10 \mathrm{~mm} \mathrm{Hg}$. ${ }^{16,21} \mathrm{Lit}-$ erature exists that also reports these same discrepancies in young subjects. ${ }^{22,23}$ The decision to use the automatic measurement for arm choice was based the difficulty of doing simultaneous readings with two mercury sphygmomanometers. On the other hand, we thought it useful to imitate common clinical practice where only a single electronic device $\mathrm{BP}$ reading is registered. Potentially toxic mercury sphygmomanometers have almost completely disappeared from the clinical setting, replaced by easily handled and readily available electronic devices. ${ }^{24}$ However, we must point out that the reference values for children and adolescents were obtained using the auscultatory method with mercury, and that the values obtained from electronic devices are considerably higher. ${ }^{12,25,26}$ Studies much larger than ours have reported similar findings. Park and collaborators, in their study done with 7208 children and adolescents in a pediatric hospital, measured BP with mercury sphygmomanometers and compared the readings with those obtained with an oscillometric device (Dinamap model 8100) in two different measurement sequences. When using the automatic monitor, the systolic and diastolic BP were an average of 10 and $5 \mathrm{~mm} \mathrm{Hg}$ higher, respectively. Contrary to our study, this author found a higher systolic BP. ${ }^{26}$ These differences are partly due to the fact that automatic devices do not directly measure the systolic and diastolic BP. Both values are calculated through algorithms specific to each device and are based on the presumed relation between oscillations (oscillometric technique).

For this reason, in cases where oscillations are less than normal, something common in children, there is in increase in the probability of erroneous readings. ${ }^{13}$ We need to emphasize the impact of the measurements obtained from our patients on their BP level classification. We found an important overestimation in the diagnosis of pre- $\mathrm{AH} / \mathrm{AH}$ with the automatic device. With this type monitor, $37.7 \%$ of the children had BP values $\geq 95$ th percentile, but with the one mercury measurement there was an impressive reduction to $7.8 \%$, and this again lowered to $5.2 \%$ when the average of the three mercury readings was used. In the case of pre$\mathrm{AH}$, we detected a prevalence of $11.6 \%, 6.4 \%$ and $5.2 \%$, respectively. These findings reinforce the need to measure BP several times before diagnosing hypertension in children and adolescents.

When analyzing the National Health and Nutrition Examination Survey (NHANES) from 2005 to 2008, in a sample of 1725 adolescents $13-18$ years old with normal weight, overweight and obesity, a BP level reclassification was found in $9 \%$ of the individuals with repeated BP measurements. In $6.2 \%$ the classification was reduced, and obesity was an important predictive factor for this change in classification. ${ }^{27}$ With the existing evidence that obesity and high BP in children and adolescents tends to persist into adulthood, screening should be obligatory from an early age for both situations in today's clinical practice.

There is a definite need for measurement studies with automatic devices in children and adolescents to establish normal limits. Until then, to more accurately identify the $\mathrm{BP}$ levels in this population, mercury readings should 
not be substituted with automatic device readings. ${ }^{28}$ On the other hand, despite the generalized use of oscillometric BP devices, only a few have been validated for clinical use in children. These can be consulted at http: //www.dableducational.org/l. ${ }^{29}$

In this study we found that BP readings in children and adolescents with obesity are not done with sufficient due diligence, despite the fact that they are a population vulnerable for the development of $\mathrm{AH}$ and cardiovascular damage; slightly over $10 \%$ of our subjects had BP values in the pre-hypertension/hypertension range. Only $3 \%$ recognized having their BP taken on a regular basis, and a third had only at least one previous reading. Other recent studies have also found a low screening rate for hypertension in the pediatric population. Information derived from a representative sample of the National Ambulatory Medical Care Survey and National Hospital Ambulatory Medical Care Survey 2000-2009 in the United States showed that only $35 \%$ of the ambulatory pediatric visits and two-thirds of the children attended by preventative medicine services were screened for hypertension. However, this percentage improved in children and adolescents with obesity, increasing to $84 \%$. The authors of this publication find it worrying that one in five of these children did not have their BP taken. ${ }^{15}$ The fact that only $39 \%$ of our study group with obesity recognized having at least one previous BP measurement is not even close to following international recommendations. A more recent study in hospitalized children screened for BP, of whom only $20 \%$ had obesity, showed that almost $55 \%$ of these subjects had never had their BP taken before. Also, those children with obesity and a family history of hypertension had a higher frequency of $\mathrm{AH} .{ }^{14}$ Although not common, there are indications of better compliance with $\mathrm{AH}$ screening guides, such as the study done by Parker and collaborators in two United States localities, where more than 103000 electronic registries of children and adolescents were analyzed. The BP screening rate by family practitioners and pediatricians was $87 \%$ and $73 \%$, respectively. ${ }^{30}$

Since BP measurement, using the auscultatory method should include the use of a cuff that covers $80 \%$ of the arm, different sizes do exist according to the requirements of each individual. In children and adolescents, just like in adults, it has been demonstrated that to use of a too-small or too-large cuff can cause an over- or underestimation of $\mathrm{BP}$, respectively. ${ }^{31,32}$

A recent study in children and adolescents to determine the effect of the cuff size on BP readings showed an overestimation in the systolic BP when a cuff smaller than appropriate for the arm circumference was used. ${ }^{33}$

Taking a BP reading when faced with childhood obesity can be particularly challenging, due to the lack of validated BP monitors and of a proper selection of different-sized cuffs that fit continually growing arm circumferences. The higher prevalence of obesity in children and adolescents in our country and in many other regions of the world is the principal cause of the increase in arm circumferences. ${ }^{34}$ Results obtained from the NHANES 2007-2010 in the United States showed that, for the 9-11 and the 12-15 years old groups, $24 \%$ and $53 \%$ of the boys, and $22 \%$ and $48 \%$ of the girls need an adult- or large adult-sized cuff, respectively. ${ }^{17}$ In our population of children with obesity, $66 \%$ required a standard adult cuff and $22 \%$ a large adult cuff. It is common to label BP cuffs according to the population it is most adequate for, usually defined by the age group where they are used, such as infant or pediatric, child, thin adult, standard adult, etc. However, given the recent panorama of thicker arms in all age groups, this type terminology should be eliminated. In this study, we practically did not use cuffs labeled "child-size". As other authors have mentioned, maybe this is the moment to revise and change cuff-size names to create more a uniform criteria, identifying them only with the circumference range where they should be used. ${ }^{34,35}$ Also, the current epidemiological obesity problem should make health care equipment manufacturers more conscience of the need to offer a larger variety of cuff sizes for general practice, pediatric and specialist settings in order to avoid erroneous decisions in the diagnosis and follow-up of $\mathrm{AH}$ caused by the use of a wrongsized cuff.

Although there is a possibility of bias in our study by first using an oscillometric monitor to measure BP, Park and collaborators detected, independently of which type reading was done first, higher $\mathrm{BP}$ with an electronic device when compared to mercury. ${ }^{26}$ Another potential bias was obtaining only one automatic reading instead of several readings, as this could have influenced the higher BP average with this device. However, since typically only one electronic measurement is done during office visits, doing the same could give us a better idea of the size of the error obtained with this oscillometric measurement present in daily clinical practice. ${ }^{36}$

\section{Conclusions}

High BP is frequently found in children with obesity, and the more severe the obesity, the higher the AH prevalence. Although BP screening is recommended from three years on, this cheap and relatively simple procedure was often not done, despite the fact that the study population was more vulnerable for cardiovascular damage. Even more, when readings are taken there is a possibility of bias when using an oscillometric device instead of a mercury-based one, evidenced by the differences in BP found when both methods are compared. Both readings are not interchangeable. The importance of BP screening in routine visits following international recommendations acquires even more transcendence when facing the current world-wide obesity epidemic, forcing medical health care providers to provide adequate monitors and cuffs for correct readings. Finally, BP should be measured several times during a medical visit for a more exact determination of BP levels, as many children with initial high BP show normal BP with repeated measurements, even during a short time frame. ${ }^{37,38}$

\section{Ethical disclosures}

Protection of human and animal subjects. The authors declare that no experiments were performed on humans or animals for this study.

Confidentiality of data. The authors declare that they have followed the protocols of their work center on the publication of patient data. 
Right to privacy and informed consent. The authors have obtained the written informed consent of the patients or subjects mentioned in the article. The corresponding author is in possession of this document.

\section{Funding}

None.

\section{Conflict of interest}

The authors declare no conflict of interest.

\section{References}

1. Gutiérrez JP, Rivera-Dommarco J, Shamah-Levy T, et al. Encuesta Nacional de Salud y Nutrición 2012. In: Resultados Nacionales. Cuernavaca, México: Instituto Nacional de Salud Pública (MX); 2012. p. 147-53.

2. Ogden CL, Carroll MD, Kit BK, et al. Prevalence of obesity and trends in body mass index among US children and adolescents, 1999-2010. JAMA. 2012;307:483-90.

3. Kelly AS, Barlow SE, Rao G, et al. Severe obesity in children and adolescents: identification, associated health risks, and treatment approaches. Circulation. 2013;128: 1689-712.

4. Wang YC, Gortmaker SL, Taveras EM. Trends and racial/ethnic disparities in severe obesity among US children and adolescents, 1976-2006. Int J Pediatr Obes. 2011;6:12-20.

5. Skinner AC, Skelton JA. Prevalence and trends in obesity and severe obesity among children in the United States, 1999-2012. JAMA Pediatr. 2014;168:561-6.

6. Ells LJ, Hancock C, Copley VR, et al. Prevalence of severe childhood obesity in England: 2006-2013. Arch Dis Child. 2015;100:631-6.

7. Nguyen JV, Robbins JM, Houck KL, et al. Severe obesity and high blood pressure among children, Philadelphia Health Centers, 2010. J Prim Care Community Health. 2014;5: $152-5$.

8. Lo JC, Chandra M, Sinaiko A, et al. Severe obesity in children: prevalence, persistence and relation to hypertension. Int J Pediatr Endocrinol. 2014;2014:3.

9. Falkstedt D, Koupil I, Hemmingsson T. Blood pressure in late adolescence and early incidence of coronary heart disease and stroke in the Swedish 1969 conscription cohort. J Hypertens. 2008;26:1313-20.

10. McCarron P, Okasha M, McEwen J, et al. Blood pressure in early life and cardiovascular disease mortality. Arch Intern Med. 2002;162:610-1.

11. Flynn J. The changing face of pediatric hypertension in the era of the childhood obesity epidemic. Pediatr Nephrol. 2013;28:1059-66.

12. National High Blood Pressure Education Program Working Group on High Blood Pressure in Children and Adolescents. The fourth report on the diagnosis, evaluation, and treatment of high blood pressure in children and adolescents. Pediatrics. 2004;114:555-76.

13. Lurbe E, Cifkova R, Cruickshank JK, et al., European Society of Hypertension. Management of high blood pressure in children and adolescents: recommendations of the European Society of Hypertension. J Hypertens. 2009;27:1719-42.

14. Stabouli S, Sideras L, Vareta G, et al. Hypertension screening during healthcare pediatric visits. J Hypertens. 2015;33:1064-8.
15. Shapiro DJ, Hersh AL, Cabana MD, et al. Hypertension screening during ambulatory pediatric visits in the United States, 20002009. Pediatrics. 2012;130:604-10.

16. Pickering TG, Hall JE, Appel LJ, et al. Recommendations for blood pressure measurement in humans and experimental animals. Part 1: blood pressure measurement in humans. Hypertension. 2005;45:142-61.

17. Ostchega Y, Hughes JP, Prineas RJ, et al. Mid-arm circumference and recommended blood pressure cuffs for children and adolescents aged between 3 and 19 years: data from the National Health and Nutrition Examination Survey, 1999-2010. Blood Press Monit. 2014;19:26-31.

18. Falkner B. Hypertension in children and adolescents: epidemiology and natural history. Pediatr Nephrol. 2010;25: 1219-24.

19. Chen X, Wang Y. Tracking of blood pressure from childhood to adulthood: a systematic review and meta-regression analysis. Circulation. 2008;117:3171-80.

20. Sun SS, Grave GD, Siervogel RM, et al. Systolic blood pressure in childhood predicts hypertension and metabolic syndrome later in life. Pediatrics. 2007;119:237-46.

21. Fonseca-Reyes S, Forsyth-MacQuarrie AM, García de Alba-García JE. Simultaneous blood pressure measurement in both arms in hypertensive and nonhypertensive adult patients. Blood Press Monit. 2012;17:149-54.

22. Grossman A, Prokupetz A, Gordon B, et al. Inter-arm blood pressure differences in young, healthy patients. J Clin Hypertens. 2013;15:575-8.

23. Fotherby MD, Panayiotou B, Potter JF. Age-related differences in simultaneous interarm blood pressure measurements. Postgrad Med J. 1993;69:194-6.

24. O'Brien E. Demise of the mercury sphygmomanometer and the dawning of a new era in blood pressure measurement. Blood Press Monit. 2003;8:19-21.

25. Podoll A, Grenier M, Croix B, et al. Inaccuracy in pediatric outpatient blood pressure measurement. Pediatrics. 2007;119:e538-43.

26. Park MK, Menard SW, Yuan C. Comparison of auscultatory and oscillometric blood pressures. Arch Pediatr Adolesc Med. 2001;155:50-3.

27. Becton LJ, Egan BM, Hailpern SM, et al. Blood pressure reclassification in adolescents based on repeat clinic blood pressure measurements. J Clin Hypertens. 2013;15: 717-22.

28. Chiolero A, Paradis G, Lambert M. Accuracy of oscillometric devices in children and adults. Blood Press. 2010;19: 254-9.

29. dabl Educational Trust Blood Pressure Monitors-Validations, Papers and Reviews. www.dableducational.org/, accessed $7 \mathrm{Apr}$ 2016.

30. Parker ED, Sinaiko AR, Daley MF, et al. Factors associated with adherence to blood pressure measurement recommendations at pediatric primary care visits, Minnesota and Colorado, 20072010. Prev Chronic Dis. 2015;12:140562.

31. Fonseca-Reyes S, García de Alba-García J, Parra-Carrillo JZ, et al. Effect of standard cuff on blood pressure readings in patients with obese arms. How frequent are arms of a large circumference? Blood Press Monit. 2003;8: 101-6.

32. Gómez-Marín O, Prineas RJ, Rastam L. Cuff bladder width and blood pressure measurement in children and adolescents. J Hypertens. 1992; 10:1235-41.

33. Muhamed PK, Olsen MH, Holm JC, et al. Cuff size influences blood pressure measurement in obese children and adolescents. Dan Med J. 2016;63:A5183.

34. Prineas RJ, Ostchega Y, Carroll M, et al. US demographic trends in mid-arm circumference and recommended blood pressure cuffs for children and adolescents: data from the National 
Health and Nutrition Examination Survey 1988-2004. Blood Press Monit. 2007;12:75-80.

35. Arafat M, Mattoo TK. Measurement of blood pressure in children: recommendations and perceptions on cuff selection. Pediatrics. 1999;104:e30.

36. Houweling ST, Kleefstra N, Lutgers HL, et al. Pitfalls in blood pressure measurement in daily practice. Fam Pract. 2006;23:20-7.
37. Osborne R, Mullin CS, Roberson PK. The variability of blood pressure measurements in children. Am J Public Health. 1983;73:1207-10.

38. Tschumi S, Noti S, Bucher BS, et al. Is childhood blood pressure higher before or after clinic consultation? Acta Paediatr. 2011;100:775-7. 